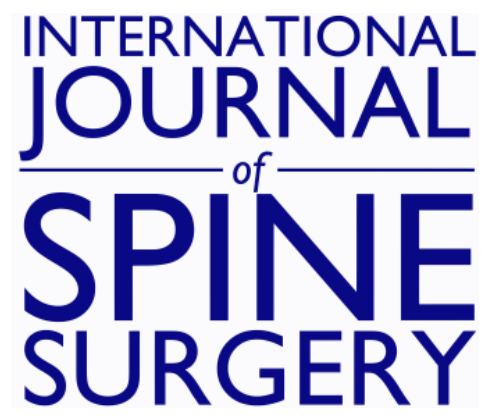

\title{
The Surgical Treatment of Single Level Multi-Focal Subarticular and Paracentral and/or Far-Lateral Lumbar Disc Herniations: The Single Incision Full Endoscopic Approach
}

\author{
James J. Yue, David L. Scott, Xiao Han and Alem Yacob
}

Int J Spine Surg 2014, 8 ()

doi: https://doi.org/10.14444/1016

http://ijssurgery.com/content/8/16

This information is current as of April 26, 2023.

Email Alerts Receive free email-alerts when new articles cite this article. Sign up at:

http://ijssurgery.com/alerts 


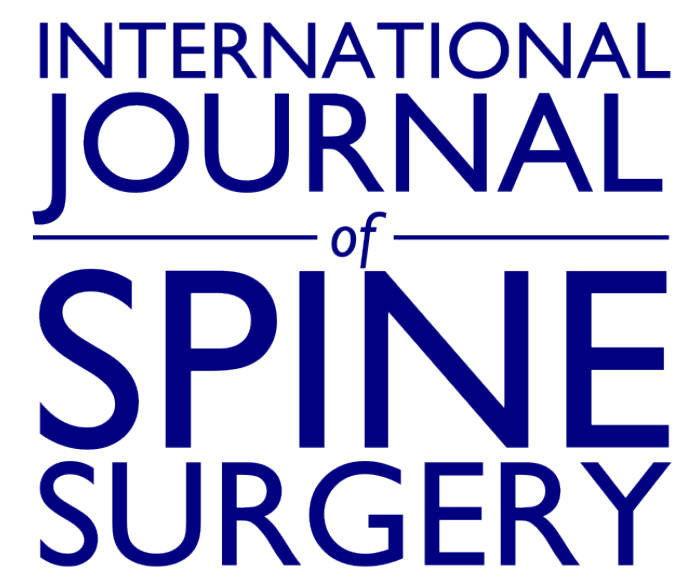

This article generously published free of charge by the International Society for the Advancement of Spine Surgery.

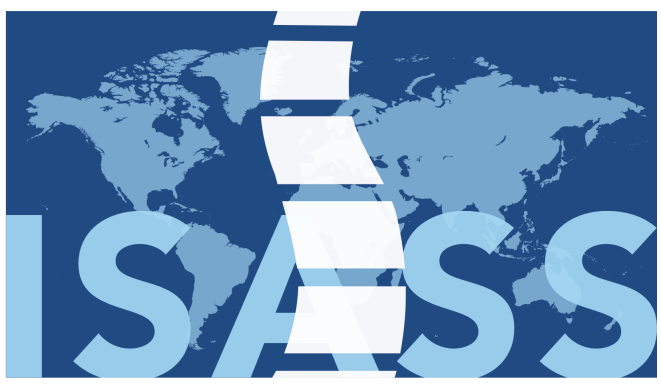

INTERNATIONAL SOCIETY for the ADVANCEMENT of SPINE SURGERY 


\section{The Surgical Treatment of Single Level Multi-Focal Subarticular and Paracentral and/or Far- Lateral Lumbar Disc Herniations: The Single Incision Full Endoscopic Approach}

James J. Yue, MD, David L. Scott, MD, Xiao Han, MD, Alem Yacob, MD

Department of Orthopaedics \& Rehabilitation, Yale University School of Medicine, New Haven CT 06520

\section{Abstract}

\section{Background}

Surgery for same level multi-focal extruded lumbar disc herniations is technically challenging and the optimal method controversial. The subarticular disc herniation may pose the most challenging subtype requiring partial or complete facetectomy with or without fusion. The far-lateral disc herniation, often treated using a Wiltse approach, can also be difficult to access especially in the obese patient. When both the subarticular and far-lateral subtypes are simultaneously present at the same level with or without a paracentral disc herniation, a total facetectomy and interbody fusion (TLIF) or a total disc replacement (TDR) may be necessary. Endoscopic surgical techniques may reduce the need for these more invasive methods.

\section{Methods}

Fifteen patients ( 6 male and 9 female) who had same level multi-focal (subarticular as well as far-lateral and/or paracentral) extruded disc herniations underwent single incision unilateral endoscopic disc excision by the same surgeon at a single institution. Patients were prospectively followed for an average of 15.3 months (range 14-18 months) and outcomes were evaluated radiographically and clinically (Visual Analogue Scale (VAS) and Oswestry Disability Index (ODI). 


\section{Results}

The mean operative time was 52 minutes with minimal blood loss in all cases. Fourteen of the 15 patients were discharged to home on the day of their surgery. The mean ODI and leg VAS scores improved from $22.9 \pm 3.2$ to $12.9 \pm 2.7(\mathrm{p}<0.005)$, and from $8.6 \pm 1.6$ to $2.1+0.4(\mathrm{p}<0.005)$, respectively.

\section{Conclusions}

After an average of 15.3 months of follow-up, the clinical and radiographic results of full endoscopic surgical treatment of single level multi-focal (subarticular as well as farlateral and/or paracentral) disc herniations are excellent. This study is a case series with mid-term follow-up (Level IV).

\section{Clinical Relevance}

Foraminal and extra-foraminal full endoscopic decompression appears to offer a safe minimally invasive solution to a complex pathologic problem.

keywords: Endoscopic Spine Surgery, Lumbar, Far-lateral, Subarticular, Paracentral, Disc Herniation

Volume 8 Article 16 - Endoscopic \& Percutaneous Special Issue doi: 10.14444/1016

\section{Introduction}

Posterior open treatment methods such as lumbar posterior discectomy, micro-lumbar discectomy, and micro-endoscopic discectomy (MED) have been used to treat uni-focal central, paracentral, or far-lateral lumbar disc herniations causing symptomatic lumbar radiculopathy. ${ }^{1-17}$ Approximately three decades ago, Kambin described the endoscopic posterolateral approach using the triangular region he termed the "safe zone". ${ }^{18-}$

Table 3. Reliability of CT Reading: Titanium Versus Stainless Steel.

${ }^{23}$ More recent research has explored the use of full endoscopic techniques to treat lumbar disc herniations at various anatomical locations. ${ }^{24-40}$

Most, if not all, of these open as well as endoscopic discectomy studies have focused on the treatment of uni-focal disc herniations. To the best of our knowledge, multi-focal herniations that include a combination of central/paracentral, subarticular, and far-lateral herniations have not been studied. Our paper explores the use of modern full endoscopic techniques in the treatment of multi-focal lumbar disc herniations at a single intervertebral level.

\section{Materials \& Methods}

This Institutional Review Board approved study enrolled patients with symptomatic and recalcitrant radicular pain secondary to multi-focal lumbar disc herniations. All patients had magnetic resonance imaging (MRI) evidence of at least 2 uni-level foci of lumbar disc herniation. The herniation foci were classified as either; (1) central/paracentral, (2) subarticular, or (3) far-lateral. 
All patients underwent preoperative MRI and computed tomography (CT) of the lumbar spine. Plain X-rays (standing antero-posterior, lateral, and flexion / extension views) were obtained preoperatively and 1 year postoperatively. Preoperative and postoperative (6 week, 6 month and 12 month) clinical outcome data (back and leg VAS and ODI scores) were collected along with clinical assessments of motor strength (graded 0-5), light touch, pain, reflexes, and proprioception. All of the cases were performed by the same surgeon at a single institution.

The surgical approach was either the intra-foraminal approach (Figure 1) as described by Reutten ${ }^{32-34}$ or the intradiscal approach described by Kambin and Yeung. ${ }^{38}$ Surgeries were performed in the prone position on a Wilson frame using fluoroscopic guidance under combined local and intravenous sedation. Spinal cord stimulation was not utilized. All patients received preoperative antibiotic prophylaxis.

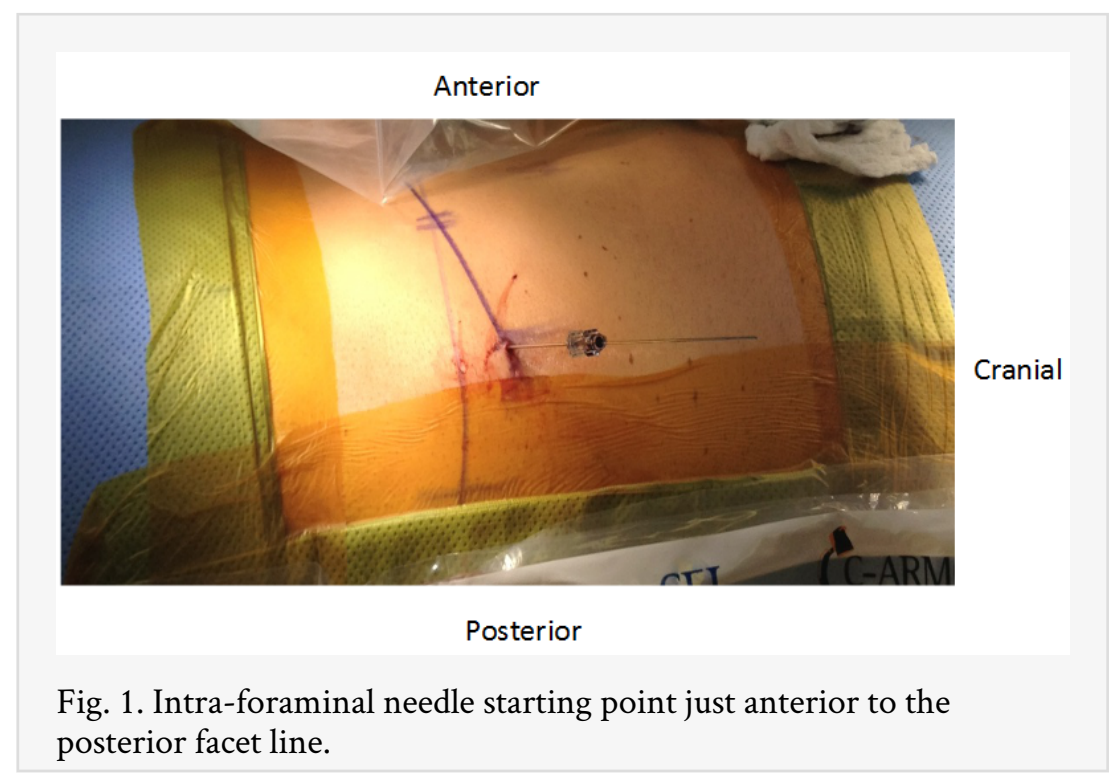

Regardless of the pattern of multi-focal disc herniation, the subarticular component was excised first prior to addressing either the intra-canal or far-lateral herniation. If the preoperative assessment of the foraminal anatomy revealed bony stenosis (especially in the inferior foraminal zone), endoscopic decompression was not performed due to the risk of pinching the nerve between the pedicle and the upwardly displaced endoscope. Even in the absence of bony foraminal stenosis, care was taken to approach the disc space from the inferior aspect of the disc and to slowly remove subarticular herniated fragments so as to not displace herniated disc material cranially towards the exiting nerve root.

\section{Results \& Statistical Methods}

Six male and 9 female patients, with an average age of 46 years (range 24-53 years), were determined to have single-level multi-focal lumbar disc herniations (Table 1). Six patients demonstrated simultaneous paracentral and subarticular herniations at the L3-4 (2) and L4-5 (4) levels; 6 patients exhibited concurrent paracentral, far-lateral, and subarticular herniations (L3-4 (1) and L4-5 (5)); and three patients were found to have subarticular and far-lateral disc herniations (L3-4 (1) and L4-5 (2)). Three patients had undergone previous decompression attempts. Mean operative time was 52 minutes with minimal 
blood losses. All patients received local/intravenous sedation for surgical anesthesia.

Fourteen of the 15 patients were discharged to home on the same day of surgery and all patients were followed for a minimum of 14 months.

Table 1. Case Distribution

\begin{tabular}{|l|l|l|l|}
\hline & $\begin{array}{l}\text { Subarticular + Paracentral/ } \\
\text { Central }\end{array}$ & $\begin{array}{l}\text { Subarticular + Far } \\
\text { lateral }\end{array}$ & $\begin{array}{l}\text { Subarticular + Far lateral and Paracentral/ } \\
\text { Central }\end{array}$ \\
\hline L3-4 & 2 & 1 & 1 \\
\hline L4-5 & 4 & 2 & 5 \\
\hline
\end{tabular}

The average Oswestry Disability Index score improved from $22.9 \pm 3.2$ to $12.9 \pm 2.7$ ( $\mathrm{p}<$ $0.005)$, and the average leg Visual Analog Scale improved from $8.6 \pm 1.6$ to $2.1 \pm 0.4$ ( $\mathrm{p}<$ $0.005)$. No significant changes in disc height or range of motion (ROM) were noted on plain radiographs. Return to work averaged 7 days postoperatively. No patients required reoperation. There were no incidental durotomies, infections, vascular or visceral injuries. One patient, 6 months following surgery, experienced isolated extensor hallucis longus (EHL) weakness without foot drop - a recurrent disc herniation was not identified on repeat imaging.

Case \#1

- 54 year old white male

- 5'10" $225 \mathrm{lb}$ BMI $31.82 \mathrm{~kg} / \mathrm{m}^{2}$

- Attorney, Non-smoker

- Injured back while lifting a $200 \mathrm{lb}$ tree 2 months prior to initial presentation

- Primary Complaint: Burning left-anterior thigh pain (minimal axial back pain)

- Preoperative Imaging: Figure 2 A \& B.

- Intraoperative Imaging: Figure $3 \mathrm{~A}, \mathrm{~B}, \& \mathrm{C}$.

- Postoperative Clinical Function: Figure 3 D. 


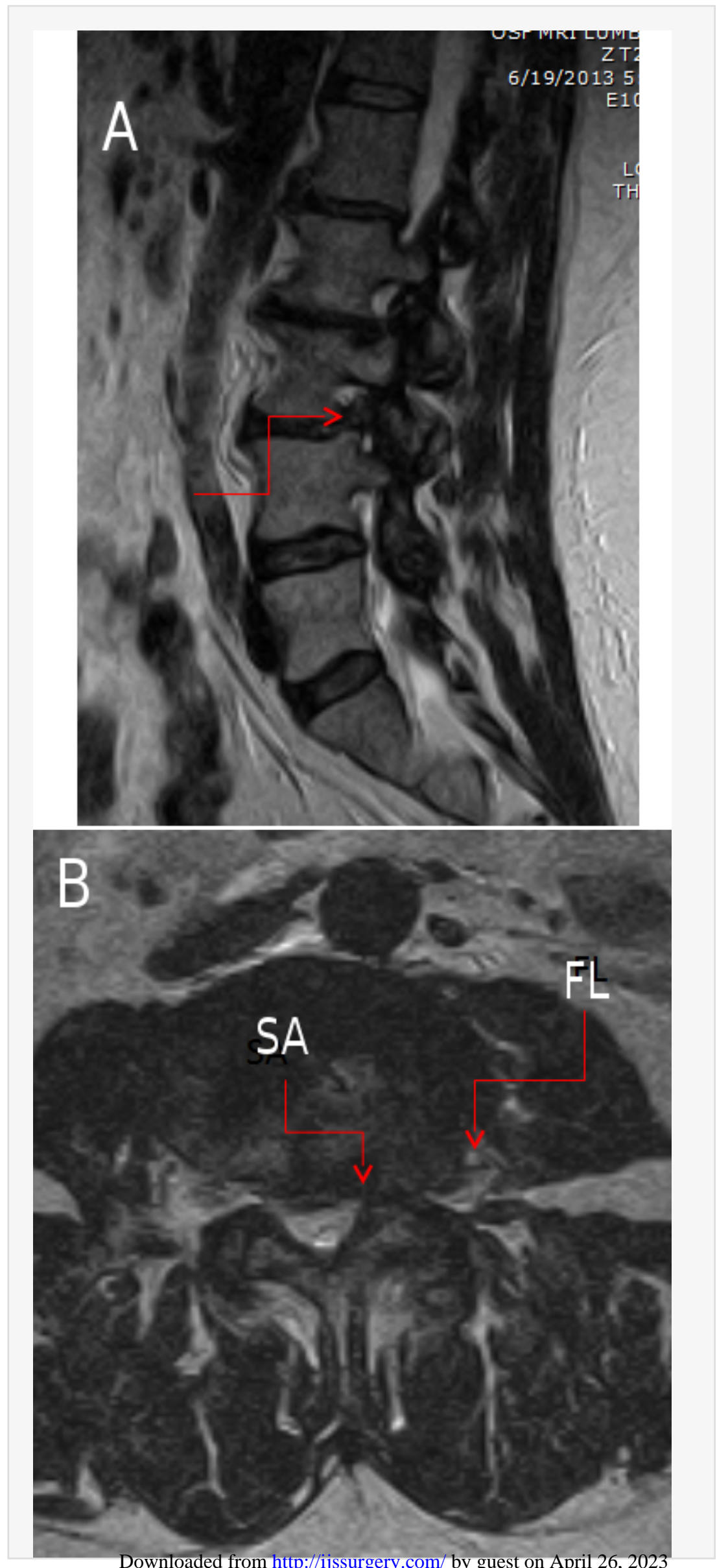


Fig. 2. A: Sagittal MRI (the red arrow identifies the foraminal herniated nucleus pulposus (HNP)). B: Sub-articular (SA) and farlateral (FL) disc herniations. 


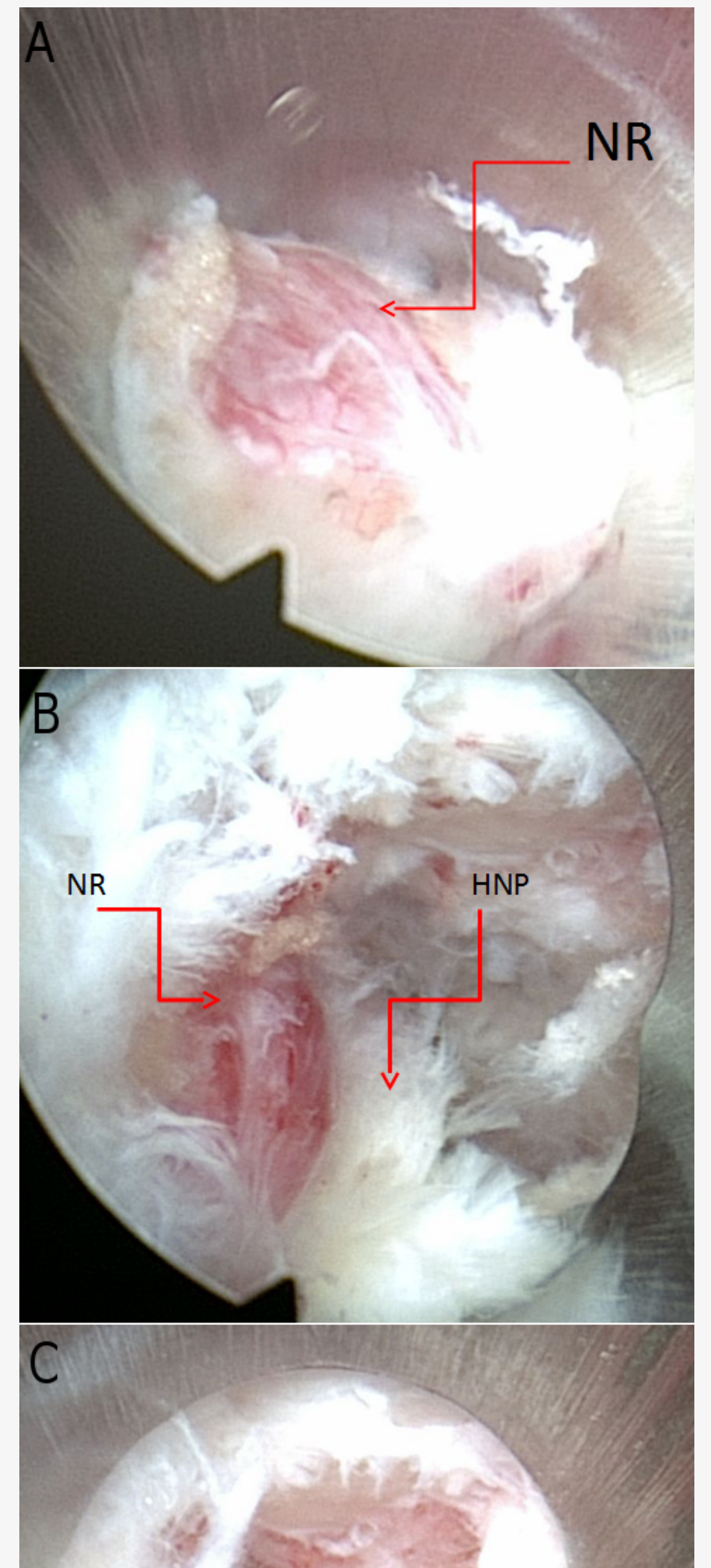

Downloaded from http://ijssurgery.com/ by guest on April 26, 2023

NR 
Fig. 3. A: Left L3 nerve root (NR) with far lateral herniated nucleus pulposus (HNP) medial to the nerve. B: L3 nerve root (NR) partially decompressed. HNP (herniated nucleus pulposus). C: L3 nerve root decompressed. Kambin (K) triangle visualized. D: Normal full left hip extension 10 days post-operative.

Case \#2

- 48 year old white female

- 5'4" $135 \mathrm{lb}$ BMI $23.2 \mathrm{~kg} / \mathrm{m}^{2}$

- Waitress, Non-smoker

- History of a hypercoagulation disorder

- Injured back while walking in deep snow

- Primary Complaint: Severe right buttock and leg pain

- Preoperative Imaging: Figure 4 A \& B.

- Intraoperative Images: Figure 4 C \& D.

- Postoperative Imaging: Figure 5 A \& B. 


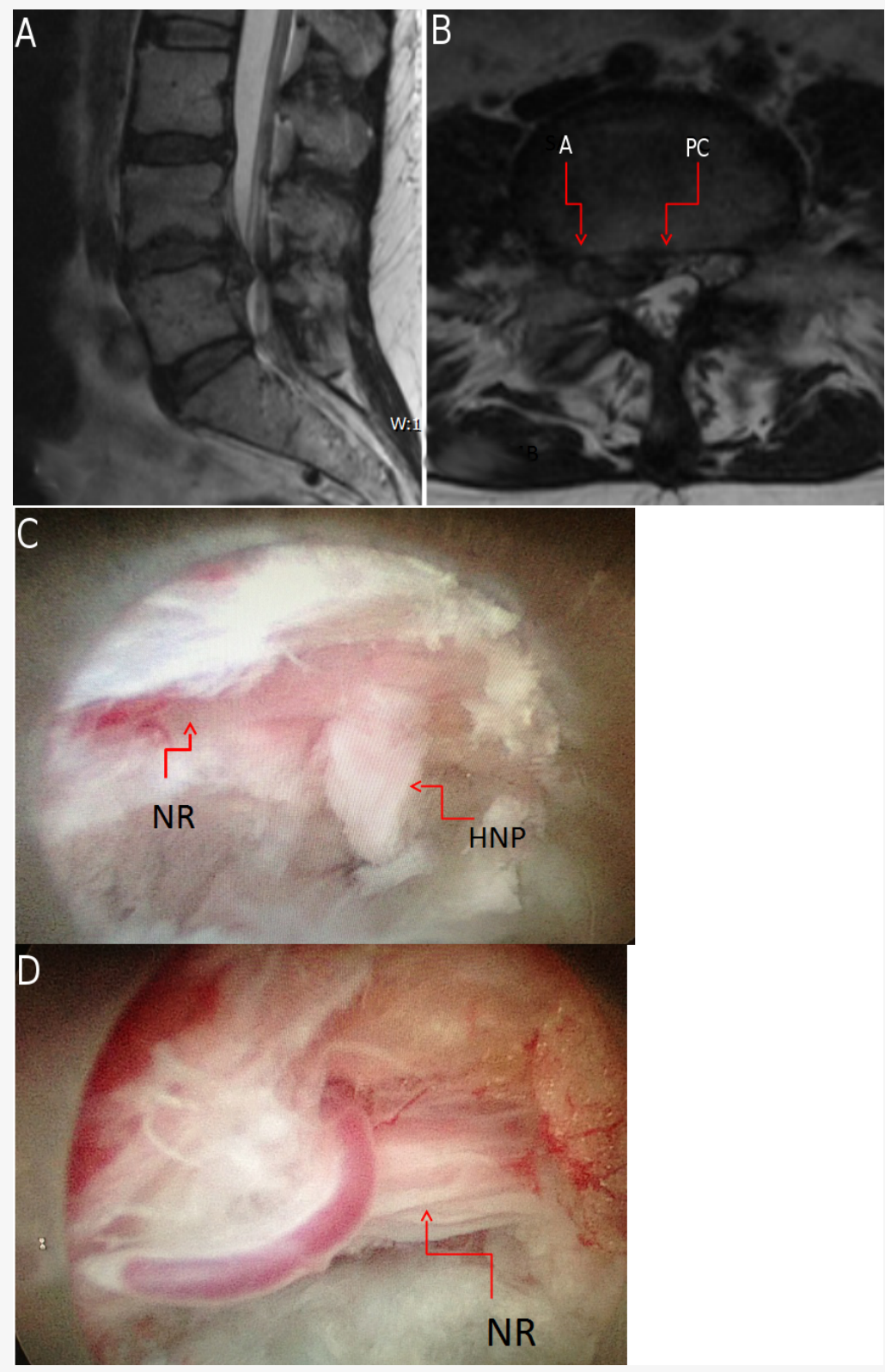

Fig. 4. A, B: Subarticular (SA) and paracentral (PC) herniated nucleus pulposus (HNP). C: Extruded disc (HNP) surrounding nerve root (NR). D: Post-discectomy, decompressed nerve root (NR) surrounded by epidural fat. 


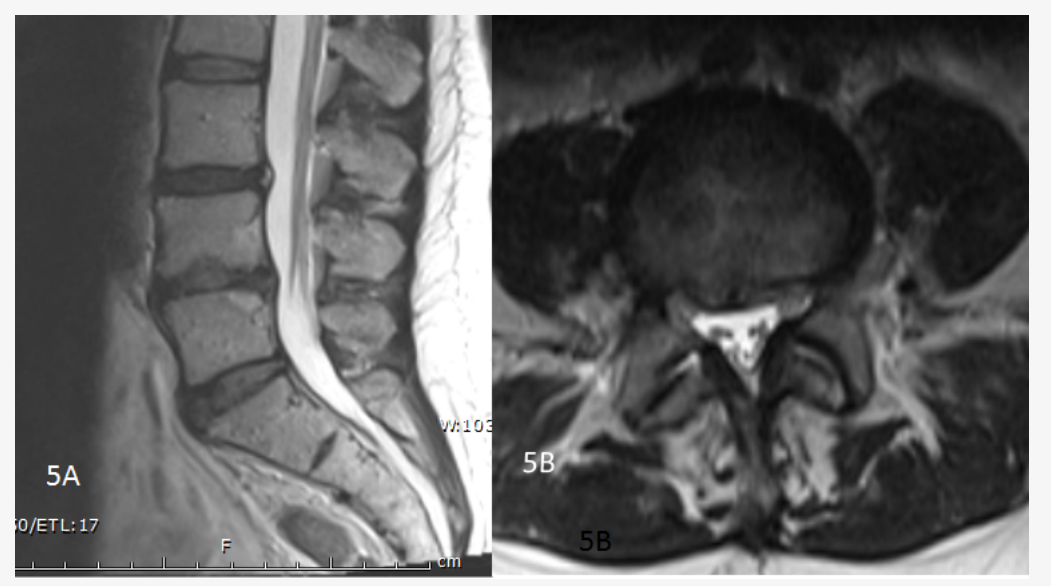

Fig. 5. A, B: Post-operative MRI 5 months after discectomy.

\section{Case \#3}

- 62 year old white female

- 5'2 $110 \mathrm{lb}$ BMI $20.3 \mathrm{~kg} / \mathrm{m}^{2}$

- History of two prior L4-5 decompressions / laminotomies by Wiltse approach

- Primary Complaint: Left buttock and leg pain

- Preoperative Imaging: Figure 6; Figure 7.

- Intraoperative Images: Figure 8; Figure 9; Figure 10. 


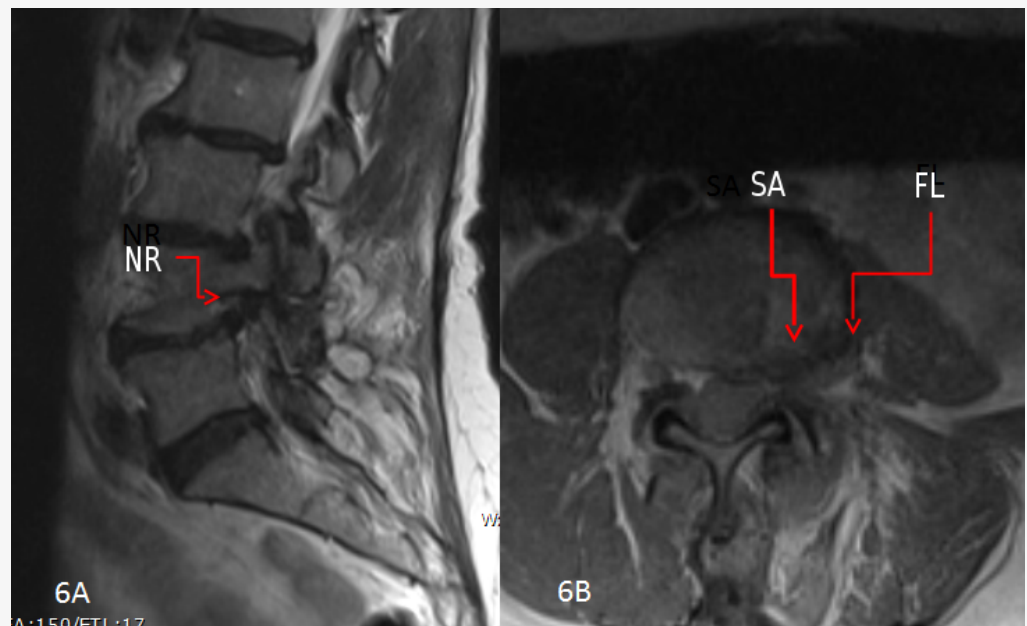

Fig. 6. A, B: Preoperative MRI demonstrating L4-5 foraminal/ subarticular herniated nucleus pulposus (HNP) and far-lateral HNP. Nerve root (NR) compression demonstrated.

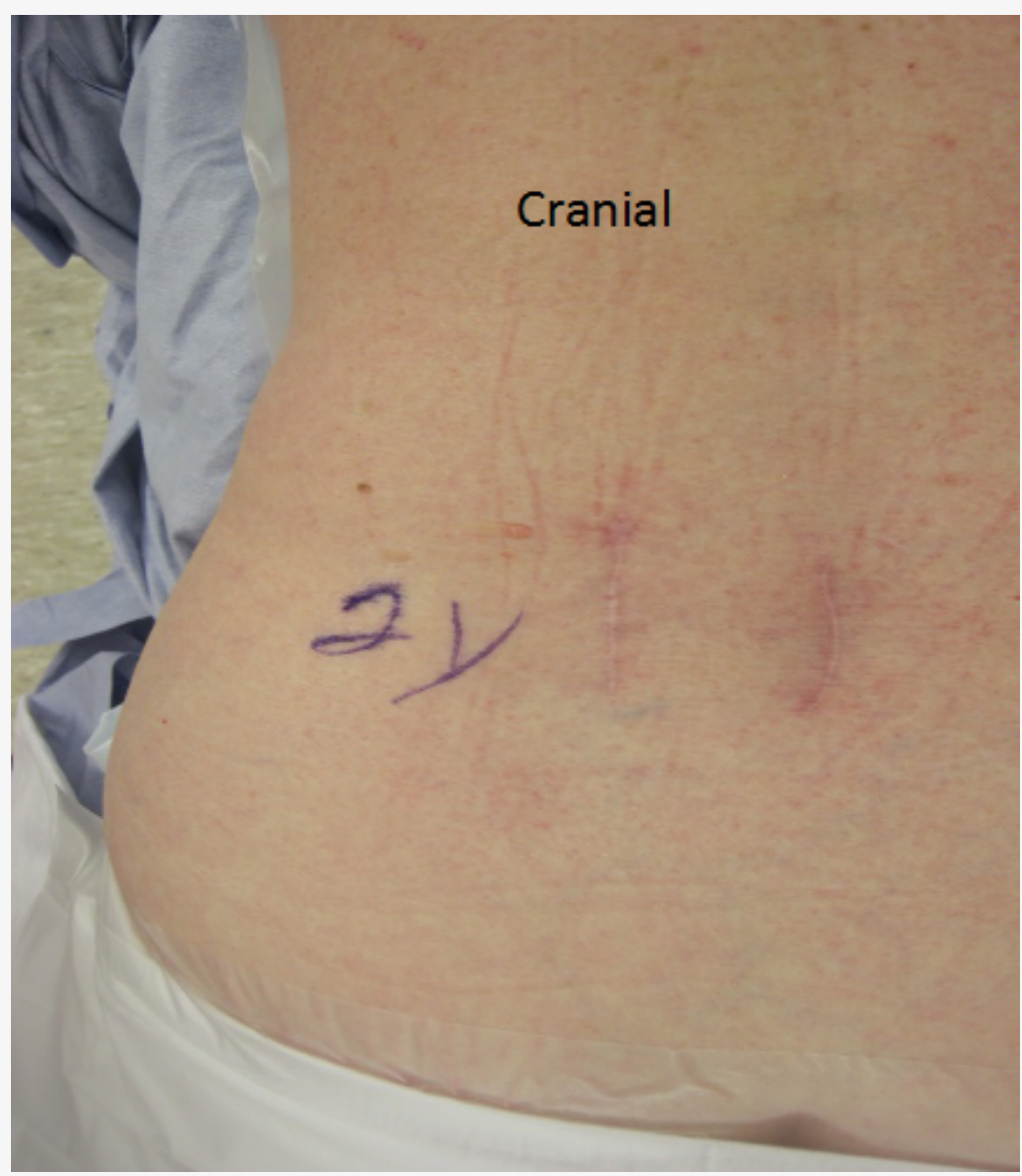

Fig. 7. Pre-operative back showing two previous surgical incisions. 


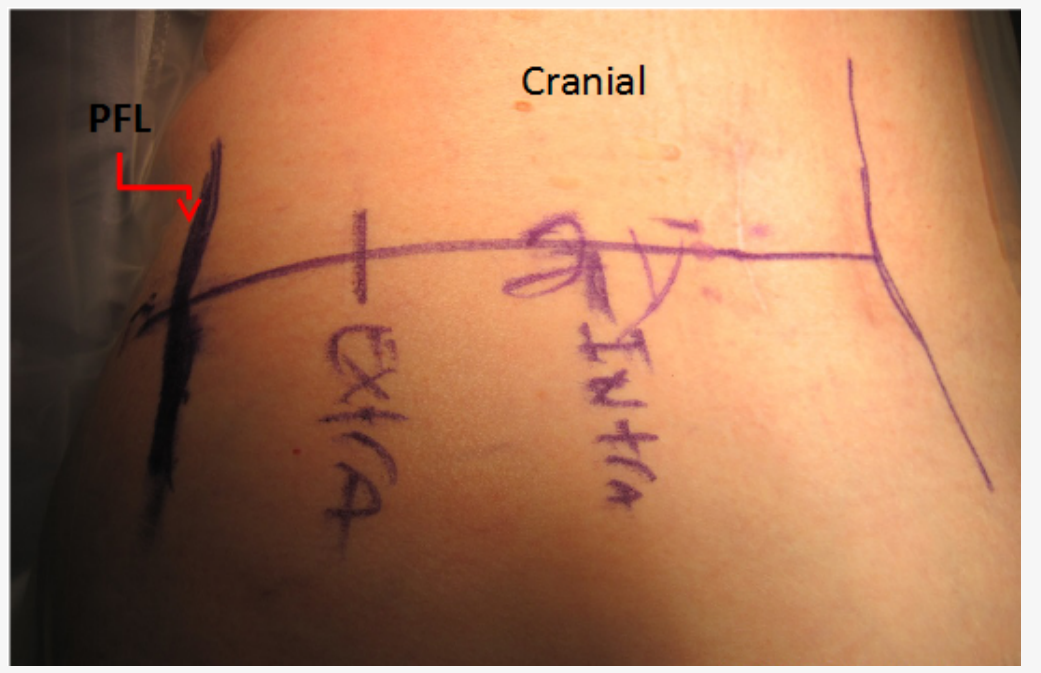

Fig. 8. Intradiscal starting (INTRA) line more medial and extra discal / intra foraminal (EXTRA) starting line more lateral. Dark line is posterior facet line (PFL). 

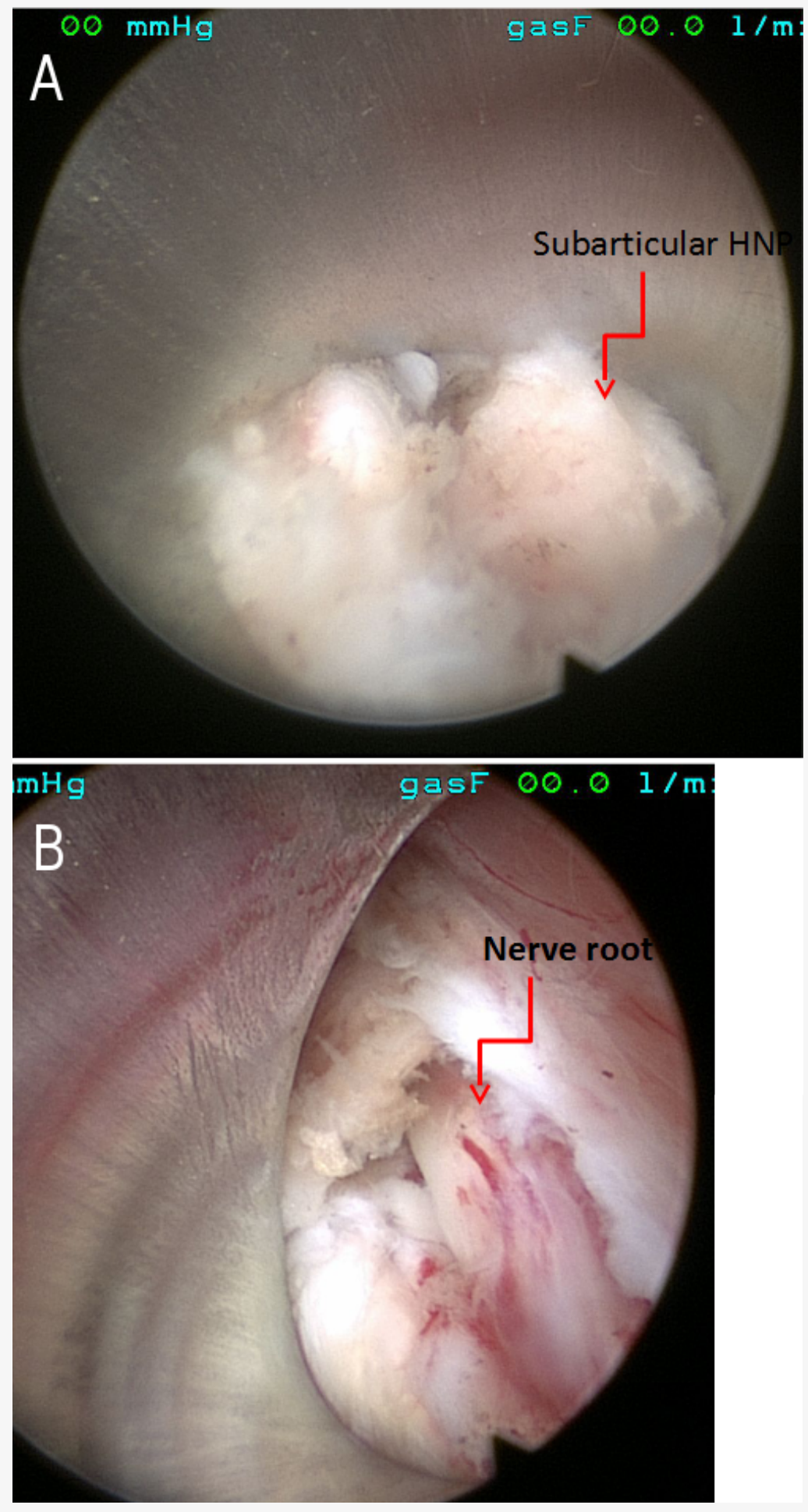

Fig. 9. A: Subarticular herniated nucleus pulposus (HNP).B: L3 nerve root. 


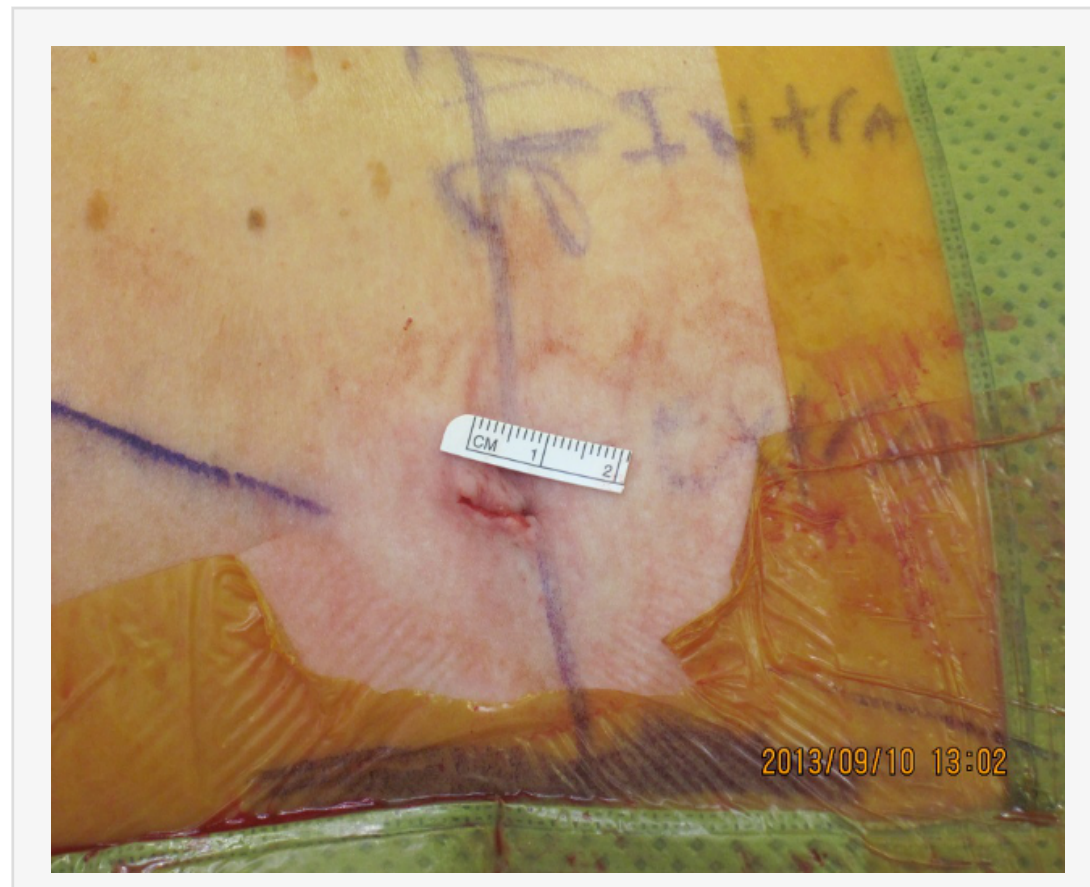

Fig. 10. Postoperative incision $(9 \mathrm{~mm})$.

Case \# 4 (Not included in study population): Uni-focal disc herniation (Figure 11).

- 30 year old white male

- 6’1'290 lb BMI $38.3 \mathrm{~kg} / \mathrm{m}^{2}$

- Presented to clinic in July and needed to be sufficiently recovered to return to work as a school teacher no later than August 15th

- No traumatic injury

- Primary Complaints: Back and bilateral buttock pain $(\mathrm{R}>\mathrm{L})$ 

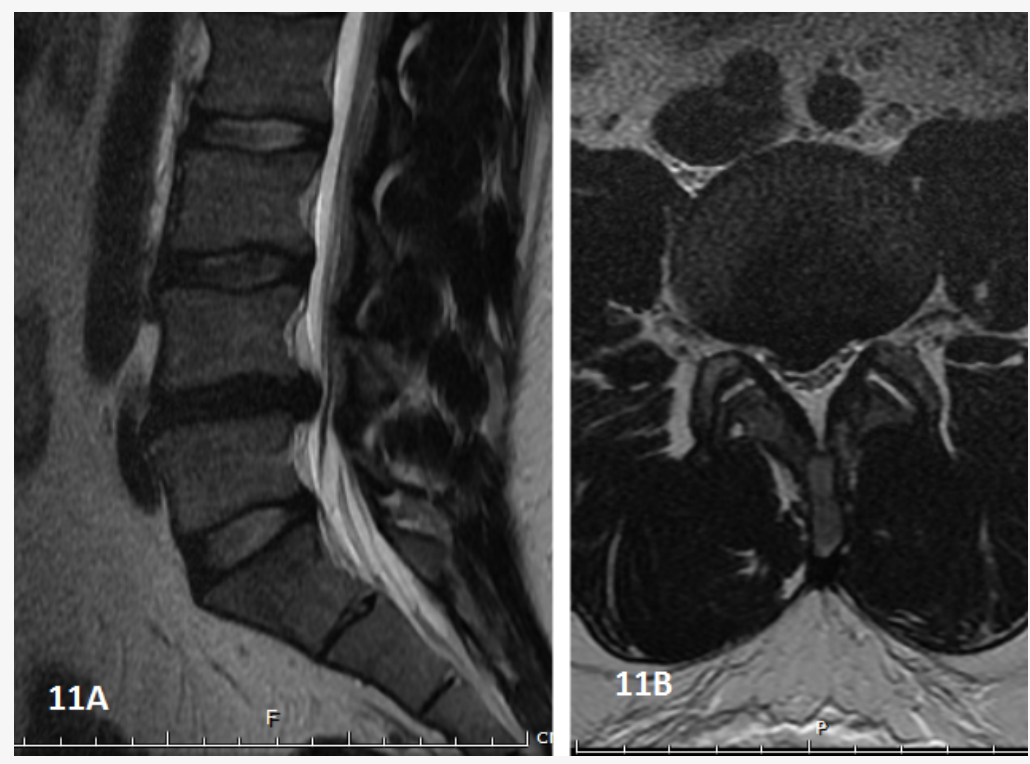

Fig. 11. A, B: MRI of uni-focal herniated nucleus pulposus (HNP).

\section{Discussion}

Traditional (posterior open and microdiscectomy) lumbar discectomy research has been focused primarily, if not exclusively, on uni-focal disc herniations (Figs 11 A and 11B). ${ }^{1-17,41-49}$ These papers have analyzed either paracentral/central or far-lateral disc herniations but have not included the sub-articular sub-type. Patients with single-level multi-focal disc herniations have been largely ignored. This study examines the surgical outcomes of patients who exhibit a multi-focal pattern of disc herniation (Figure 2; Figure 3; Figure 4; Figure 5; Figure 6; Figure 7; Figure 8; Figure 9; Figure 10). Specifically, we enrolled patients who, at a single lumbar level, experienced a subarticular disc herniation coupled with either a far-lateral and / or a paracentral / central disc herniation. Approximately one quarter of our patients had previous decompression attempts.

Kitagawa recently published a case report on the endoscopic treatment of the simultaneously occurring "intracanal and extracanal" lumbar herniation ${ }^{28}$. Numerous other articles have been published delineating the efficacy of the endoscope for decompressing the far-lateral, paracentral, or subarticular lumbar disc herniation. ${ }^{24,25,27,29,30,32,34,36,38-40,50-65}$ We present the outcomes of patients with multifocal disc herniations who were similarly treated utilizing a full endoscopic technique with direct visualization of the respective discs and neurological structures. Our patients experienced significant short-term improvement in their radicular and axial back symptoms with maintenance of this recovery at an average of 14 months postoperatively.

Endoscopic techniques require a detailed understanding of intra- and extra-foraminal anatomy. The enhanced optics of the endoscope permits intra-canal visualization of the foramen - an essential component of the successful treatment of the multi-focal lumbar disc herniation. In any pattern of the multi-focal disc herniation, excision of the subarticular component should occur first followed by removal of either the intra-canal or 
far-lateral herniation. The far-lateral disc component is approached inferiorly sweeping cranially with the endoscope to protect the exiting nerve root. Initial needle placement should be performed to facilitate this caudal to cranial inclination of the endoscope.

Postoperatively, patients were permitted to immediately resume their usual activities of daily living and return to clerical forms of work within 7 days. Clerical levels of work were maintained for 6 weeks and then restrictions slowly reduced over a period of 4 weeks. No intra-operative complications were experienced. One case of mild EHL weakness occurred 8 weeks postoperatively but without a radiographically apparent recurrent disc herniation (Fig 5A and 5B). No other neurological problems were encountered.

Potential deficiencies of our study include: (1) the relatively short follow-up, (2) the mixed population of patients -3 patients with prior lumbar decompressions, and (3) the absence of patients with L5-S1 disc herniations.

The multi-focal lumbar disc herniation has been considered the most difficult pattern of disc disruption to approach surgically often mandating dual approaches and / or fusion techniques. Our early term data suggest that a uni-portal single incision full endoscopic approach can satisfactorily decompress these challenging patterns of disc herniation. Careful preoperative clinical and radiographic assessment utilizing plain X-rays, CT, and MRI is essential to assess the foraminal anatomy for bony facet overgrowth that could necessitate a foraminoplasty prior to discectomy and to identify calcification of the lateral disc complex. In cases that involve decompression of a far-lateral disc herniation, local / intravenous sedation should be considered to permit awake intra-operative neurological monitoring. Activities of daily living and clerical forms of employment can be safely initiated within 7 days following discectomy. Uni-focal endoscopic cases should be attempted prior to undertaking the multi-focal pattern of disc herniation, as the latter requires an advanced level of technical proficiency.

\section{References}

1. Cervellini P, De Luca GP, Mazzetto M, et al. Micro-endoscopic-discectomy (MED) for far lateral disc herniation in the lumbar spine. Technical note. Acta Neurochir Suppl 2005;92:99.

2. Best NM, Sasso RC. Success and safety in outpatient microlumbar discectomy. J Spinal Disord Tech 2006;19:334-7.

3. Wu X, Zhuang S, Mao Z, et al. Microendoscopic discectomy for lumbar disc herniation: surgical technique and outcome in 873 consecutive cases. Spine (Phila Pa 1976) 2006;31:2689-94.

4. Chao Z, Yue Z, Tong-wei C, et al. Microendoscopic discectomy, a less traumatic procedure for lumbar disk herniation. Chin J Traumatol 2007;10:311-4.

5. O'Toole JE, Eichholz KM, Fessler RG. Minimally invasive far lateral microendoscopic discectomy for extraforaminal disc herniation at the lumbosacral junction: cadaveric dissection and technical case report. Spine $J$ 2007;7:414-21.

6. Yeung AT, Yeung CA. Minimally invasive techniques for the management of lumbar disc herniation. Orthop Clin North Am 2007;38:363-72; abstract vi. 
7. Arts MP, Peul WC, Koes BW, et al. Management of sciatica due to lumbar disc herniation in the Netherlands: a survey among spine surgeons. J Neurosurg Spine 2008;9:32-9.

8. Lurie JD, Faucett SC, Hanscom B, et al. Lumbar discectomy outcomes vary by herniation level in the Spine Patient Outcomes Research Trial. J Bone Joint Surg Am 2008;90:1811-9.

9. Chang S-S, Fu T-S, Liang Y-C, et al. Results of microendoscopic discectomy performed in the 26 cases with a minimum 3 years follow-up. Chang Gung Med $J$ 2009;32:89-97.

10. Kunert P, Kowalczyk P, Marchel A. Minimally invasive microscopically assisted lumbar discectomy using the METRx X-Tube system. Neurol Neurochir Pol 2010;44:554-9.

11. Garg B, Nagraja UB, Jayaswal A. Microendoscopic versus open discectomy for lumbar disc herniation: a prospective randomised study. J Orthop Surg (Hong Kong) 2011;19:30-4.

12. Postacchini F, Postacchini R. Operative management of lumbar disc herniation : the evolution of knowledge and surgical techniques in the last century. Acta Neurochir Suppl 2011;108:17-21.

13. Rahimi-Movaghar V, Rasouli M, Shokraneh F, et al. Minimally invasive discectomy versus microdiscectomy/ discectomy for symptomatic lumbar disc herniation. J Inj Violence Res 2012;4.

14. Wang M, Zhou Y, Wang J, et al. A 10-year follow-up study on long-term clinical outcomes of lumbar microendoscopic discectomy. J Neurol Surg A Cent Eur Neurosurg 2012;73:195-8.

15. Blamoutier A. Surgical discectomy for lumbar disc herniation: surgical techniques. Orthop Traumatol Surg Res 2013;99:S187-96.

16. Kimball J, Yew A, Lu DC. Minimally invasive surgery for lumbar microdiscectomy. Neurosurg Focus 2013;35 Suppl:Video15.

17. Ozer AF, Keskin F, Oktenoglu T, et al. A novel approach to the surgical treatment of lumbar disc herniations: indications of simple discectomy and posterior transpedicular dynamic stabilization based on carragee classification. Adv Orthop 2013;2013:270565.

18. Kambin P, Sampson S. Posterolateral percutaneous suction-excision of herniated lumbar intervertebral discs. Report of interim results. Clin Orthop Relat Res 1986:37-43.

19. Kambin P, Brager MD. Percutaneous posterolateral discectomy. Anatomy and mechanism. Clin Orthop Relat Res 1987:145-54.

20. Kambin P. Percutaneous lumbar diskectomy. JAMA 1989;262:1776.

21. Kambin P, Schaffer JL. Percutaneous lumbar discectomy. Review of 100 patients and current practice. Clin Orthop Relat Res 1989:24-34.

22. Kambin P. Arthroscopic microdiskectomy. Mt Sinai J Med 1991;58:159-64.

23. Schaffer JL, Kambin P. Percutaneous posterolateral lumbar discectomy and decompression with a 6.9-millimeter cannula. Analysis of operative failures and complications. J Bone Joint Surg Am 1991;73:822-31.

24. Chen H-T, Tsai C-H, Chao S-C, et al. Endoscopic discectomy of L5-S1 disc herniation via an interlaminar approach: Prospective controlled study under local and general anesthesia. Surgical Neurology International 2011;2:93. 
25. Dezawa A, Mikami H, Sairyo K. Percutaneous endoscopic translaminar approach for herniated nucleus pulposus in the hidden zone of the lumbar spine. Asian Journal of Endoscopic Surgery 2012;5:200-3.

26. Doi T, Harimaya K, Matsumoto Y, et al. Endoscopic decompression for intraforaminal and extraforaminal nerve root compression. Journal of Orthopaedic Surgery and Research 2011;6:16.

27. Jasper GP, Francisco GM, Telfeian AE. A retrospective evaluation of the clinical success of transforaminal endoscopic discectomy with foraminotomy in geriatric patients. Pain Physician 2013;16:225-9.

28. Kitagawa Y, Sairyo K, Shibuya I, et al. Minimally invasive and simultaneous removal of herniated intracanal and extracanal lumbar nucleus pulposus with a percutaneous spinal endoscope. Asian Journal of Endoscopic Surgery 2012;5:183-6.

29. Liu G, Zhao J-N, Dezawa A. Endoscopic decompression combined with interspinous process implant fusion for lumbar spinal stenosis. Chinese Journal of Traumatology = Zhonghua chuang shang za zhi / Chinese Medical Association 2008;11:364-7.

30. Liu K-X, Massoud B. Transforaminal endoscopic lumbar procedure for disc herniations: a "between" technique. Surgical Technology International 2010;19:203-10.

31. Oertel JMK, Mondorf Y, Gaab MR. A new endoscopic spine system: the first results with "Easy GO". Acta neurochirurgica 2009;151:1027-33.

32. Ruetten S, Komp M, Merk H, et al. Use of newly developed instruments and endoscopes: full-endoscopic resection of lumbar disc herniations via the interlaminar and lateral transforaminal approach. Journal of Neurosurgery Spine 2007;6:521-30.

33. Ruetten S, Komp M, Merk H, et al. Full-endoscopic interlaminar and transforaminal lumbar discectomy versus conventional microsurgical technique: a prospective, randomized, controlled study. Spine 2008;33:931-9.

34. Ruetten S, Komp M, Merk H, et al. Surgical treatment for lumbar lateral recess stenosis with the full-endoscopic interlaminar approach versus conventional microsurgical technique: a prospective, randomized, controlled study. Journal of neurosurgery Spine 2009;10:476-85.

35. Ruetten S, Meyer O, Godolias G. Endoscopic surgery of the lumbar epidural space (epiduroscopy): results of therapeutic intervention in 93 patients. Minimally Invasive Neurosurgery : MIN 2003;46:1-4.

36. Tsou PM, Alan Yeung C, Yeung AT. Posterolateral transforaminal selective endoscopic discectomy and thermal annuloplasty for chronic lumbar discogenic pain: a minimal access visualized intradiscal surgical procedure. The Spine Journal : Official Journal of the North American Spine Society 2004;4:564-73.

37. Yeom K-s, Choi Y-s. Full endoscopic contralateral transforaminal discectomy for distally migrated lumbar disc herniation. Journal of Orthopaedic Science : Official Journal of the Japanese Orthopaedic Association 2011;16:263-9.

38. Yeung AT. The evolution of percutaneous spinal endoscopy and discectomy: state of the art. The Mount Sinai Journal of Medicine, New York 2000;67:327-32.

39. Yeung AT, Yeung CA. Advances in endoscopic disc and spine surgery: foraminal approach. Surgical Technology International 2003;11:255-63.

40. Yeung AT, Yeung CA. In-vivo endoscopic visualization of patho-anatomy in painful degenerative conditions of the lumbar spine. Surgical Technology International 2006;15:243-56. 
41. Weinstein JN, Lurie JD, Tosteson TD, et al. Surgical versus nonoperative treatment for lumbar disc herniation: four-year results for the Spine Patient Outcomes Research Trial (SPORT). Spine (Phila Pa 1976) 2008;33:2789-800.

42. Chae KH, Ju CI, Lee SM, et al. Strategies for Noncontained Lumbar Disc Herniation by an Endoscopic Approach : Transforaminal Suprapedicular Approach, Semi-Rigid Flexible Curved Probe, and 3-Dimensional Reconstruction CT with Discogram. $J$ Korean Neurosurg Soc 2009;46:312-6.

43. Parker SL, Xu R, McGirt MJ, et al. Long-term back pain after a single-level discectomy for radiculopathy: incidence and health care cost analysis. J Neurosurg Spine 2010;12:178-82.

44. Silverplats K, Lind B, Zoega B, et al. Clinical factors of importance for outcome after lumbar disc herniation surgery: long-term follow-up. Eur Spine J 2010;19:1459-67.

45. Veresciagina K, Spakauskas B, Ambrozaitis KV. Clinical outcomes of patients with lumbar disc herniation, selected for one-level open-discectomy and microdiscectomy. Eur Spine J 2010;19:1450-8.

46. Ahsan K, Najmus S, Hossain A, et al. Discectomy for primary and recurrent prolapse of lumbar intervertebral discs. J Orthop Surg (Hong Kong) 2012;20:7-10.

47. Cheng J, Wang $\mathrm{H}$, Zheng $\mathrm{W}$, et al. Reoperation after lumbar disc surgery in two hundred and seven patients. Int Orthop 2013;37:1511-7.

48. Matsumoto M, Watanabe K, Hosogane N, et al. Recurrence of lumbar disc herniation after microendoscopic discectomy. J Neurol Surg A Cent Eur Neurosurg 2013;74:222-7.

49. Nie H, Hao J, Peng C, et al. Clinical outcomes of discectomy in octogenarian patients with lumbar disc herniation. J Spinal Disord Tech 2013;26:74-8.

50. Abili M, Naruie B, Akhavan Sigari R. Treatment outcomes of 130 patients underwent an endoscopic discectomy. Journal of Injury \& Violence research 2012;4.

51. Choi G, Lee S-H, Lokhande P, et al. Percutaneous endoscopic approach for highly migrated intracanal disc herniations by foraminoplastic technique using rigid working channel endoscope. Spine 2008;33:E508-15.

52. Chumnanvej S, Kesornsak W, Sarnvivad P, et al. Full endoscopic lumbar discectomy via interlaminar approach: 2-year results in Ramathibodi Hospital. Journal of the Medical Association of Thailand = Chotmaihet thangphaet 2011;94:1465-70.

53. Hoogland T, van den Brekel-Dijkstra K, Schubert M, et al. Endoscopic transforaminal discectomy for recurrent lumbar disc herniation: a prospective, cohort evaluation of 262 consecutive cases. Spine 2008;33:973-8.

54. Jasper GP, Francisco GM, Telfeian AE. Endoscopic transforaminal discectomy for an extruded lumbar disc herniation. Pain Physician 2013;16:E31-5.

55. Kaushal M, Sen R. Posterior endoscopic discectomy: Results in 300 patients. Indian Journal of Orthopaedics 2012;46:81-5.

56. Kim CH, Chung CK. Endoscopic interlaminar lumbar discectomy with splitting of the ligament flavum under visual control. Journal of Spinal Disorders \& Techniques 2012;25:210-7.

57. Kim HS, Ju CI, Kim SW, et al. Endoscopic transforaminal suprapedicular approach in high grade inferior migrated lumbar disc herniation. Journal of Korean Neurosurgical Society 2009;45:67-73.

58. Komp M, Hahn P, Merk H, et al. Bilateral operation of lumbar degenerative central spinal stenosis in full-endoscopic interlaminar technique with unilateral approach: 
prospective 2-year results of 74 patients. Journal of Spinal Disorders \& Techniques 2011;24:281-7.

59. Kuonsongtum V, Paiboonsirijit S, Kesornsak W, et al. Result of full endoscopic uniportal lumbar discectomy: preliminary report. Journal of the Medical Association of Thailand $=$ Chotmaihet thangphaet 2009;92:776-80.

60. Liu T, Zhou Y, Wang J, et al. Clinical efficacy of three different minimally invasive procedures for far lateral lumbar disc herniation. Chinese Medical Journal 2012;125:1082-8.

61. Matsumoto M, Hasegawa T, Ito M, et al. Incidence of complications associated with spinal endoscopic surgery: nationwide survey in 2007 by the Committee on Spinal Endoscopic Surgical Skill Qualification of Japanese Orthopaedic Association. Journal of Orthopaedic Science : official journal of the Japanese Orthopaedic Association 2010;15:92-6.

62. Ozturk C, Tezer M, Aydogan M, et al. Posterior endoscopic discectomy for the treatment of lumbar disc herniation. Acta Orthopaedica Belgica 2006;72:347-52.

63. Ruetten S, Komp M, Merk H, et al. Recurrent lumbar disc herniation after conventional discectomy: a prospective, randomized study comparing fullendoscopic interlaminar and transforaminal versus microsurgical revision. Journal of spinal disorders \& techniques 2009;22:122-9.

64. Wang B, Lu G, Liu W, et al. Full-endoscopic interlaminar approach for the surgical treatment of lumbar disc herniation: the causes and prophylaxis of conversion to open. Archives of Orthopaedic and Trauma Surgery 2012;132:1531-8.

65. Zhou Y, Zhang C, Wang J, et al. Minimally invasive strategies and options for farlateral lumbar disc herniation. Chinese Journal of Traumatology = Zhonghua chuang shang za zhi / Chinese Medical Association 2008;11:259-66.

\section{Disclosures}

Dr. Yue is a Consultant/Lecturer for Richard Wolf Spine. No other authors declare financial disclosures.

\section{Corresponding Author}

Address correspondence to James J. Yue, MD, Department of Orthopaedics and Rehabilitation, Yale University School of Medicine, P.O. Box 208071, New Haven, CT 06520-8071.

Copyright (C) 2014 ISASS - International Society for the Advancement of Spine Surgery. To see more or order reprints or permissions, see http://ijssurgery.com. 